\title{
Tecnologias digitais de informação e comunicação na aquisição de conhecimentos científicos para alunos surdos: uma revisão integrativa da literatura
}

\author{
Digital information and communication technologies on the acquisition of scientific knowledge to \\ deaf students: an integrative literature review
}

Las tecnologías digitales de la información y la comunicación en la adquisición de conocimientos científicos para estudiantes sordos: una revisión bibliográfica integradora

\author{
Clarice Fabiano Costa Palavissini \\ ORCID: https://orcid.org/0000-0003-3419-6526 \\ Universidade Estadual do Paraná, Brasil \\ E-mail: clarice_fc@hotmail.com \\ Kelly Regina Linzmeier de Lima \\ ORCID: https://orcid.org/0000-0002-3343-7239 \\ Universidade Estadual do Paraná, Brasil \\ E-mail: kellylinzmeier@hotmail.com \\ Luciana Paula Vieira de Castro \\ ORCID: https://orcid.org/0000-0003-3344-2924 \\ Universidade Tecnológica Federal do Paraná, Brasil \\ E-mail: professoralucianacastro@hotmail.com \\ Dartel Ferrari de Lima \\ ORCID: https://orcid.org/0000-0002-3633-9458 \\ Universidade Estadual do Paraná, Brasil \\ E-mail: dartelferrari07@gmail.com
}

\begin{abstract}
Resumo
Este artigo trata de uma revisão integrativa da literatura que tem o objetivo de evidenciar as principais características da utilização de Tecnologias Digitais de Informação e Comunicação (TDIC) para o suporte visual didáticopedagógico utilizado no ensino de alunos surdos, como ferramenta disponível para oportunizar novas relações de comunicação em contextos sociais cotidianos. Foram consultadas publicações da comunidade científica nas bases de dados Medical Literature and Retrivial System onLine e Literatura Latino-Americana e do Caribe em Ciências da Saúde, no período de 2010 a 2020. Onze estudos foram selecionados para a análise, dos quais, sete deles foram obtidos em periódicos internacionais. A revisão identificou duas concepções acerca da surdez e como elas são abordadas temporalmente. A primeira, clínico-terapêutica, ocupa-se com o diagnóstico da surdez e a reabilitação do surdo. A segunda, socioantropológica, ocupa-se em perceber a surdez como diferença cultural e não como uma patologia. Desse modo, evidenciou-se nesta pesquisa que as TDIC são utilizadas por duas perspectivas diferentes ambas com o foco na qualidade de vida do sujeito surdo. A primeira como ferramentas didático-pedagógicas sendo suporte visual para o aluno surdo e a outra como tecnologia para fins de reparo no defeito orgânico do indivíduo, a surdez.
\end{abstract}

Palavras-chave: Surdez; Tecnologia; Inclusão; Acessibilidade; Qualidade de vida.

\begin{abstract}
This paper is an integrative literature review that aims to emphasize the main characteristics of using Digital Information and Communication Technologies (TDIC) to the pedagogical and didactic visual support in daily social context. Publications of the scientific community were consulted on the Medical Literature and Retrivial System onLine data base and on Caribean and Latin American Literature about Health Science, between 2010 and 2020. Eleven researches were selected to analysis and, among them, seven were obtained on International Periodicals. The review identified two conceptions about the deafness and how they are approached through time. The first, clinical and therapeutic, deals with the deafness diagnostic and with the deaf rehabilitation. The second, socioanthropological, deals with perceiving deafness as a cultural difference, not as a pathology. Thus, it was evident in this research that TDIC are used by two different perspectives, both with a focus on the quality of life of the deaf person. The first as didactic-pedagogical tools being a visual support for the deaf student and the other as a technology for the purpose of repairing the individual's organic defect, deafness.
\end{abstract}

Keywords: Deafness; Technology; Inclusion; Accessibility; Quality of life. 


\begin{abstract}
Resumen
Este artículo es una revisión integradora de la literatura que pretende destacar las principales características del uso de las Tecnologías Digitales de la Información y la Comunicación (TDIC) para el apoyo didáctico-pedagógico visual utilizado en la enseñanza de alumnos sordos, como herramienta disponible para proporcionar nuevas relaciones de comunicación en contextos sociales cotidianos. Se consultaron las publicaciones de la comunidad científica en las bases de datos Sistema de Literatura Médica y Retrivial en Línea y de Literatura Latinoamericana y Caribe en Ciencias de la Salud en el período de 2010 a 2020. Se seleccionaron once estudios para el análisis, siete de los cuales se obtuvieron de revistas internacionales. La revisión identificó dos concepciones sobre la sordera y cómo se abordan a lo largo del tiempo. El primero, clínico-terapéutico, se ocupa del diagnóstico y la rehabilitación de los sordos. La segunda, socioantropológica, se ocupa de percibir la sordera como una diferencia cultural y no como una patología. Así, en esta investigación se hizo evidente que los TDIC se utilizan desde dos perspectivas diferentes, ambas con un enfoque en la calidad de vida de la persona sorda. El primero como herramientas didáctico-pedagógicas siendo un soporte visual para el alumno sordo y el otro como una tecnología con el fin de reparar el defecto orgánico del individuo, la sordera.
\end{abstract}

Palabras clave: Sordera; Tecnología; Inclusión; Accesibilidad; Calidad de vida.

\title{
1. Introdução
}

No âmbito escolar, as formas de ensinar tendem a alterações que acompanhem as mudanças sociais contemporâneas. Principalmente, quando o momento exige, em foco está um vírus letal, SARS-CoV-2 5, e o isolamento social se faz necessário. O que parecia enredo de ficção científica, Novo Coronavírus, assolou a humanidade em meados de 2019 (OPAS, 2020). Nesse sentido, estratégias pedagógicas precisaram ser repensadas independentemente do nível de ensino. Assim, as aulas baseadas no padrão mecânico de agir e centradas no professor têm a eficiência questionada (Rosa et al., 2017). Observa-se, intensivamente, a partir de 2020, a utilização progressiva de meios de fazer saber mediado por tecnologias digitais de informação e comunicação (TDIC). Isso fornece alternativas que, quando adequadamente aplicadas, podem auxiliar os professores, as escolas e os alunos no processo de ensino e aprendizagem (Moran, 2006).

A crise sanitária causada pela pandemia de Covid-19 obrigou o afastamento social como uma das formas de amenizar a disseminação do vírus. Esse ato intensificou as orientações para a utilização de TDIC para o ensino emergencial remoto (ERE), adotado por grande parte das escolas (Previtali \& Fagiani, 2020). Desse modo, à medida que se amplia o uso de TDIC como ferramentas didático-pedagógicas interativas, procura-se propiciar a construção de um conjunto de técnicas e métodos transformadores de modo a não comprometer as possibilidades de quem as utilizam (Moreira \& Simões, 2017).

$\mathrm{O}$ ato de ensinar não dispensa ferramentas que revelam as competências dos estudantes, bem como aquelas que diversificam as estratégias do ensino (Moreira \& Simões, 2017). Assim, se faz necessário considerar a possibilidade das ferramentas e recursos disponíveis, bem como na capacitação daqueles que farão uso, para nortear a prática educativa implementada por essas novas tecnologias (Ferrarini et al., 2019), (Barros \& Olímpio, 2016).

Não é raro que alunos surdos ingressem no ensino superior não só com barreiras comunicacionais, mas também com um importante déficit na aprendizagem dos níveis anteriores de escolarização. Desse modo, não se afasta a possibilidade de várias questões estarem envolvidas nesse processo, como o contexto social, os métodos de ensino que esse aluno esteve inserido, as faltas ou falhas no processo de transmissão do conhecimento, o desinteresse pessoal, entre outros (Bisol et al., 2010).

É nesse cenário, rapidamente delineado, que as TDIC se apresentam como recurso possível para auxiliar no vencimento de barreiras de comunicação. Dessa forma, uma das estratégias para a difusão de conhecimento e comunicação para as pessoas surdas é a janela com o intérprete de Língua Brasileira de Sinais (Libras) ${ }^{1}$ como ferramentas de interação virtual para o ensino-aprendizagem por práticas pedagógicas mediadas por meios digitais, como aplicativos com os conteúdos,

${ }^{1}$ Entende-se como Libras a forma de comunicação e expressão com estrutura gramatical própria, em que o sistema linguístico de transmissão de ideias e fatos e de natureza visual-motora constituem um sistema linguístico oriundo de comunidades de brasileiros surdos (Brasil, 2002). 
tarefas, notificações ou ainda aulas síncronas e assíncronas como nas plataformas do Teams (Microsoft), Google Classroom, Google Meet, Zoom, entre outros.

Estas estratégias foram pensadas para possibilitar que os estudos dessem prosseguimento, inclusive, às pessoas surdas a compreender o conteúdo das informações de forma acessível, oportunizando a inclusão no contexto pandêmico formas diferentes delas serem informadas (Febrapils, 2020). Apesar das evidências da contribuição das TDIC como ferramentas de comunicação, um passo crucial a ser mais bem compreendido trata da relação desse contributo ao ensino de alunos surdos. Nessa perspectiva, para elucidar essa lacuna do conhecimento este estudo tem como objetivo identificar, na literatura científica, e evidenciar as principais características da utilização das TDIC como suporte visual didático-pedagógico utilizado no ensino de alunos surdos e os benefícios por meio do aporte visual para a educação inclusiva, como ferramenta disponível para oportunizar novas relações de conhecimento e comunicação em contextos sociais cotidianos.

\section{Procedimentos Metodológicos}

A opção pela revisão integrativa se justifica por ser um mecanismo de busca de ampla abordagem metodológica entre as revisões, possibilitando incluir vários delineamentos de estudos para uma análise completa do fenômeno na busca por compreender o fenômeno da educação do surdo em tempos de pandemia. Estabelece, também, dados da literatura teórica e empírica, além de incorporar definições de conceitos, revisão de teorias, evidências e análise de problemas metodológicos particulares, gerando um panorama consistente e compreensível de conceitos complexos, teorias ou problemas relacionados ao foco deste estudo (Souza et al., 2010).

A revisão integrativa oportunizou alavancar este estudo, buscando semelhanças e ambiguidades nos artigos de referência disponíveis digitalmente e de acesso público. Para a busca de artigos na literatura, realizou-se um rastreamento nas bases de dados Literatura Latino-Americana e do Caribe em Ciências da Saúde (Lilacs) e Medical Literature Analysis and Retrieval Sistem online (Medline). Para a seleção dos artigos, foram utilizados os seguintes descritores e suas agregações nos idiomas português e inglês: "Tecnologias Digitais", "Tecnologias de Informação", "Tecnologias de Comunicação", com definição booleana AND para os descritores "surdez e Libras".

Os critérios de inclusão para a seleção dos artigos foram: artigos publicados em português ou inglês; artigos na íntegra, de acesso gratuito revisado por pares, com retrato do tema referente à revisão integrativa; e indexados nos referidos bancos de dados, no período de 2010 a 2020. Foram excluídas as réplicas de artigos e aqueles cujos resumos ou títulos desviavam dos objetivos da revisão.

\section{Resultados}

Foram eleitos e analisados 11 artigos, sendo 4 deles em língua portuguesa. O Quadro 1 apresenta a síntese dos artigos selecionados. 
Quadro 1: Síntese dos estudos selecionados, segundo a autoria, ano e local de publicação e abordagem focal do artigo, coletados na base de dados do Lilacs e Medline, no período de 2010 a 2020.

\begin{tabular}{|c|c|c|c|}
\hline Autor (es) & Ano & Periódico & Estudo \\
\hline $\begin{array}{c}\text { Bisol, C. A., } \\
\text { Bremm, E. S. \& Valentini, C. B. }\end{array}$ & 2010 & $\begin{array}{l}\text { Psicol. esc. } \\
\quad \text { Educ. }\end{array}$ & Blogs de adolescentes surdos: escrita e construção de sentidos \\
\hline $\begin{array}{c}\text { Hyde, M., } \\
\text { Punch, R. \& } \\
\text { Komesaroff, L. }\end{array}$ & 2010 & $\begin{array}{l}\text { J Deaf Stud } \\
\text { Deaf Educ }\end{array}$ & $\begin{array}{l}\text { Tomada de decisão sobre o implante coclear: pais fazendo } \\
\text { escolhas por seus filhos surdos }\end{array}$ \\
\hline $\begin{array}{l}\text { Julstrom, S., } \\
\text { Kozma-Spytek, L. \& } \\
\text { Isabelle, S. }\end{array}$ & 2011 & $\begin{array}{l}\text { J Am Acad } \\
\text { Audiol }\end{array}$ & $\begin{array}{l}\text { Requisitos de desempenho de compatibilidade para aparelhos } \\
\text { auditivos no modo telecoil para dispositivos sem fio e sem } \\
\text { cabo: níveis de sinal magnético }\end{array}$ \\
\hline $\begin{array}{l}\text { Stinson, M. S., } \\
\text { Elliot, L. B. \& } \\
\text { Easton, D. }\end{array}$ & 2014 & $\begin{array}{l}\text { J Deaf Stud } \\
\text { Deaf Educ }\end{array}$ & $\begin{array}{l}\text { Retenção de conteúdo em cursos de graduação em ciências, } \\
\text { tecnologia, engenharia e matemática por alunos surdos/com } \\
\text { deficiência auditiva e outros alunos do ensino superior com } \\
\text { anotações baseadas no computador tablet }\end{array}$ \\
\hline Libório et. al. ${ }_{2}$ & 2015 & $\begin{array}{l}\text { Rev. bras. educ. } \\
\text { espec. }\end{array}$ & $\begin{array}{l}\text { Resiliência e processos protetivos de adolescentes com } \\
\text { deficiência física e surdez incluídos em escolas regulares }\end{array}$ \\
\hline Smith, L. S. & 2015 & Nursing & Sintonize a segurança para pacientes com deficiência auditiva \\
\hline Leite, S. S. & 2017 & Enfermagem & $\begin{array}{c}\text { Construção do roteiro do vídeo educativo para pessoas surdas } \\
\text { sobre o uso do coito interrompido }\end{array}$ \\
\hline $\begin{array}{l}\text { Carvalho, M. E., Cavalcanti, W. M. A. } \\
\text { \& } \\
\text { Silva, J. A. }\end{array}$ & 2019 & Rev. CEFAC & $\begin{array}{c}\text { Ensino de língua portuguesa para surdos: uma revisão } \\
\text { integrativa da literatura }\end{array}$ \\
\hline Carvalho, D. S. \& Pedruzzi, C. M. & 2019 & Distúrb. comun & $\begin{array}{l}\text { Uso do sistema de frequência modulada por estudantes com } \\
\text { perda auditiva }\end{array}$ \\
\hline $\mathrm{Au}$, et. al.; & 2019 & Int J Audiol & $\begin{array}{l}\text { Tecnologia de aparelho auditivo binaural sem fio para uso do } \\
\text { telefone e ouvir no ruído do vento }\end{array}$ \\
\hline Shew, A. & 2020 & Nature & $\begin{array}{l}\text { Deixe a covid-19 expandir a conscientização sobre a tecnologia } \\
\text { da deficiência }\end{array}$ \\
\hline
\end{tabular}

Fonte: Elaborado pelos autores.

O processo de busca dos trabalhos nas respectivas bases de dados informadas identificou 80 registros, destes, foram excluídos 53 por encontrar-se em duplicidade ou incompletos. Dos 27 trabalhos apontados após filtro inicial, analisaram-se o título e o resumo dos artigos, excluindo outros 16 trabalhos por fuga do tema proposto. No refinamento do processo, restaram 11 trabalhos, lidos na íntegra e considerados de acordo para a análise por conveniência, conduzida com o discurso pretendido a atender o objeto deste estudo.

A pesquisa demonstrou que com os descritivos, nas referidas bases de dados, da forma como foi abordada, a busca nos revela duas perspectivas para o uso das TDIC, tanto como ferramentas pedagógicas sendo suporte visual para o aluno surdo quanto como tecnologia para fins de reparo no defeito orgânico do indivíduo. Dos 11 estudos selecionados 4 destacam o uso das TDIC como ferramentas auxiliares para avaliação audiológica como nos trabalhos dos autores (Julstrom et al., 2011), (Smith, 2015), (Au, 2019) e (Shew, 2020). Os 7 estudos restantes abordam, de forma geral, como as TDIC podem ser excelentes ferramentas didático-pedagógicas para fazer com que o aluno surdo incluso possa ter acesso ao conhecimento.

\section{Discussões}

Quando tratamos de temas da área da surdez a dicotomia educação e saúde são relacionadas, sempre promovendo um debate interessante. Por essa razão, apresentamos um pouco do que encontramos na literatura a esse respeito. Nesse contexto, 
alunos surdos e suas famílias que anseiam por um desenvolvimento escolar satisfatório, muitas vezes, se deparam com duas visões no cenário da surdez.

A primeira aborda a visão clínico-terapêutica que prima pelo diagnóstico e pela reabilitação para a inclusão social do sujeito surdo, utilizando as tecnologias para a correção do defeito orgânico com maior brevidade possível. A segunda, ao fazer a expressão oral depender de uma necessidade fisiológica e, ao conceber a linguagem unicamente como referencial neurobiológico, aproxima a possibilidade de as pessoas surdas encontrarem-se com as redes linguísticas visuais por meio das línguas de sinais (LS), estabelecendo o viés socioantropológico (Palavissini \& Lima, 2021).

A carência de suporte pedagógico visual em aulas de variados cursos, observada a partir de vivências de um dos autores deste artigo como Tradutora e Intérprete de Língua de Sinais (TILS), evidenciou que, em alguns momentos do processo de mediação da informação, é perceptível a falha no suporte visual para suprir o apoio à língua de sinais (LS). Desta maneira, o input linguístico ${ }^{2}$ para os alunos surdos pode ser prejudicado por falha no processo da transposição linguística. Tendo em mente que para que ocorra a comunicação entre as partes, ambos necessitam conhecer do que se trata. Por essa razão, O apoio visual promove a interação e entendimento, uma vez que os surdos se apropriam do conhecimento e interagem pelo uso da visão.

Palavissini e Lima (2021) afirmam que a vida acadêmica para o público surdo é desafiadora. Primeiramente, há a dificuldade encontrada para o ingresso, com frequência esses alunos dependem de terceiros para fazerem suas inscrições por não compreenderem termos da língua portuguesa. No ingresso as barreiras comunicacionais ficam evidentes, pois, é sabido que são poucos os professores que têm domínio da língua de sinais e em muitos lugares há escassez do profissional intérprete o que dificulta a permanência e conclusão. Os autores enfatizam a importância de se ter um ambiente favorável e exaltam a importância de métodos e didáticas que possibilitem a integração entre os surdos e ouvintes. Neste contexto, necessitam de auxílio na ambientação para integrar-se ao convívio. Isto evita a evasão dos surdos, principalmente, se o ambiente não é hostil. "A barreira a ser ultrapassada é a falta de conhecimento, entretanto, ocorrem outras formas de obstáculo mais difíceis que são as barreiras atitudinais. Elas são invisíveis, pois, muitas vezes, não oportunizam que uma pessoa surda mostre sua capacidade" (Palavissini \& Lima, 2021, p. 5).

Bochernitsan (2021, p. 03) afirma que a utilização conjunta e organizada de elementos visuais, como imagens, fotografias, desenhos, gráficos e esquemas, proporciona comunicação visual efetiva. Corroborando as autoras Fernandes e Rios (1998) apontam que o estímulo adequado é fundamental para que a aprendizagem ocorra e as estratégias devem ser testadas considerando a especificidade linguística.

Para maximizar o efeito de informar com recurso didático-pedagógico para alunos surdos, a LS associada aos recursos visuais, como os aplicativos digitais possibilitados por meio das TDIC, podem potencializar a inclusão do aluno ao meio bilíngue e singular de apropriação de informações. Ambos os meios corroboram para o input linguístico dos alunos, sejam eles surdos ou ouvintes. Esta proposta se alinha ao consenso do qual o aluno surdo, para compreender os elementos do mundo, faz uso exponencial dos recursos visuais e esse posicionamento reforça a possibilidade de utilização de diferentes estratégias didáticas, como a janela de intérprete, presentes nas plataformas digitais para garantir a acessibilidade (Furtado, 2013); (Marques, 2020).

A escolha da expressão TDIC aponta para uma perspectiva que compreende os surdos no contexto tecnológico contemporâneo, relacionado aos avanços na aquisição de informação e conhecimento científico por meio da LS. Isso sugere

\footnotetext{
${ }^{2} \mathrm{O}$ input linguístico: refere-se a todas as experiências proporcionadas pelo uso que os demais fazem da linguagem em suas interações e, especialmente, ao se comunicar com o próprio sujeito (Borges \& Salomão, 2003).
} 
que a tecnologia da informação amplia a sua importância para a comunidade surda e para a difusão do uso de Libras (Corrêa \& Cruz, 2019).

A lei de Libras ainda garante a inserção do ensino da língua nos cursos de formação de Educação Especial, Fonoaudiologia e de Magistério, nos níveis médio e superior, como parte integrante dos Parâmetros Curriculares Nacionais (PCNs). Contudo, a Libras não poderá substituir a modalidade escrita da língua portuguesa (Brasil, 2002).

$\mathrm{O}$ aspecto visual da escrita também permite a inserção dos alunos surdos no âmbito linguístico dos ouvintes, enquanto aprendem a escrita como segunda língua. Desse modo, quando se une os recursos das TDIC com a escrita, as trocas de informações entre surdos e as interações de comunicação deixaram de ocorrer apenas na forma presencial, conforme ressaltam as autoras (Karnopp et al., 2011). Dessa forma, são estabelecidas relações singulares entre os registros visuais e tempo-espaço, possibilitando outras formas de compartilhamento e trocas de significados potencializando a apreensão de conhecimento entre os integrantes das comunidades surdas, tanto presencialmente quanto por plataformas digitais.

Conforme aponta Vercelli (2020), no contexto do ensino remoto emergencial, as adaptações às TDIC devem contemplar a perspectiva bilíngue. Dessa forma, o aluno surdo compartilha da experiência dos demais alunos, apropriando-se e sentindo-se incluso no processo de aprendizagem dos conteúdos científicos. O interesse atual dos alunos por tecnologias, especialmente os surdos, ampara o uso dessas ferramentas para minimizar a defasagem na aprendizagem e na interação com os demais envolvidos.

Neste cenário, a reflexão acerca das TDIC serem utilizadas como facilitadores de comunicação; seja entre os surdos ou com pessoas ouvintes. Assim, apesar das evidências da contribuição de novas tecnologias da informação como ferramenta de comunicação, um passo crucial a ser melhor compreendido, trata-se da celeridade e pouquíssimo treinamento para fins escolares dessas ferramentas entre as pessoas surdas (Palavissini \& Lima, 2021).

A interação por meio das ferramentas tecnológicas ainda pode despertar nos alunos surdos o interesse por conteúdos curriculares e extracurriculares diversos. As pesquisadoras Perlin e Strobel (2008, p. 28), asseveram que "o surdo é um sujeito que produz cultura baseada na experiência visual e requer uma educação fundamentada nessa sua diferença cultural". As autoras destacam ainda que:

[...] a Constituição que assegura o direito a diferentes expressões culturais no povo brasileiro, faz antever a necessidade de serem respeitados os direitos culturais dos surdos. Para tanto já há uma série de legislações em relação à educação do surdo, bem como em outros espaços sociais onde o surdo interage adquirindo o conhecimento, garantindo sua fundamentação cultural (Perlin \& Strobel, 2008, p. 32).

Corroborando com as autoras Corrêa e Cruz (2019, p. 27), enfatizam que os "ambientes virtuais de ensino e aprendizagem (AVEAs) são um conjunto de ferramentas digitais que favorecem o compartilhamento de informações para o gerenciamento da aprendizagem". Os autores ainda acrescentam que

Com a evolução dos sistemas de transmissão de dados pela internet, a transferência de vídeos tem se tornado cada vez mais fácil e rápida, o que corrobora o uso da língua de sinais nos AVEAs. De fato, estudos sobre o uso da língua de sinais em sites têm mostrado que eles facilitam a navegação de surdos na internet, uma vez que, quando os vídeos estão presentes, os surdos ficam menos desorientados (visitam menos páginas em busca da informação pretendida) do que quando estão navegando apenas por meio de hyperlinks textuais (Corrêa \& Cruz, 2019, P. 27).

Além disso, a forma de organização por meio de categorias e subcategorias auxilia na busca de informações, em que os surdos têm acesso tanto do código em língua de sinais quanto dos códigos em texto. Infelizmente, muitas vezes, os vídeos em língua de sinais em AVEAs são usados somente para traduzir o conteúdo principal da página, enquanto os sistemas de navegação permanecem com informações textuais (Corrêa \& Cruz, 2019). 
Podemos perceber com nosso estudo duas concepções que compõem o cenário sobre a surdez. Em um primeiro momento, a visão clínico-terapêutica, que prima pelo diagnóstico e a reabilitação para inserção do sujeito surdo em sociedade, utilizando as tecnologias para correção do defeito orgânico.

Do outro lado, temos a concepção socioantropológica, que percebe o sujeito surdo como ser social. Isso aponta a necessidade de ampliar a produção científica na área. Por esse viés, percebemos que o modelo socioantropológico propõe que a surdez seja vista como uma diferença cultural e linguística.

Nas reflexões a respeito da inclusão as autoras, Bisol et. al., (2010, p. 392), "o conceito socioantropológico de surdez prevalece entre os pesquisadores brasileiros" e "as temáticas de maior interesse são a linguagem e a língua, o desenvolvimento cognitivo e relações familiares". As pesquisadoras verificaram as contribuições da psicologia brasileira para o estudo da surdez e apontam que há uma parcela da população que tem uma característica própria - comunica-se por meio da língua de sinais reconhece-se como integrante de uma comunidade com cultura própria, constituída por pessoas que se percebem como seres potenciais e não limitados por um defeito orgânico.

Segundo Moran (2006), há várias formas de adquirir conhecimento. Essas formas se diferenciam conforme se apresentam as diferenças de objetivo e do meio sociocultural. Uma das formas usuais é o processamento lógico-sequencial, em que o conhecimento é construído progressivamente e de forma ordenada. Dessa forma, as relações mediadas pela hipertextualidade, que se estabelecem nas interações com o outro, ganham novos significados. A comunicação se apresenta ligada à outras palavras, a construção do pensamento é sequencial, lógica, coerente, porém, sem seguir uma única trilha, como em ondas que vão ramificando-se em diversas outras.

Hoje, cada vez mais, devido aos últimos acontecimentos, principalmente no campo das legislações, o processamento de informações pelos meios audiovisuais vem sendo utilizado com o intuito de garantir a qualidade efetiva da interpretação remota para a LS, com a inclusão da janela de intérprete a partir do uso de interação virtual. Promovendo a mediação de várias linguagens superpostas, compõem a inclusão como um mosaico que se conecta dando significados (Febrapils, 2020).

Moran (2006) justifica que o conhecimento se estabelece no processo rico de interação externo e interno. Nesse processo, conseguimos compreender melhor o mundo e os outros, equilibrando os processos de interação e de interiorização. E, pela interação, seja de forma tradicional ou virtual, entramos em contato com tudo o que nos rodeia. No entanto, a compreensão da mensagem só se completa com a interiorização, com o processo de síntese pessoal de reelaboração do que é captado pela interação. As crianças, os jovens sintonizados com esta forma de informação, quando lidam com textos, facilitando o texto conectado por meio de links, o hipertexto. Enfim, as formas de informação multimídia e hipertextual estão em franca evolução e podem se constituir em ferramentas úteis a favor do ensino.

Para que essas tecnologias sejam utilizadas com qualidade, é necessário pensar as TDIC como ferramentas de abertura, passando pelo sensorial, emocional e pelo racional na integração das tecnologias na educação, ao invés de ferramenta de controle educacional, conforme apregoa Moran (2013):

As tecnologias chegaram na escola, mas estas sempre privilegiaram mais o controle a modernização da infraestrutura e a gestão do que a mudança. Os programas de gestão administrativa estão mais desenvolvidos do que os voltados à aprendizagem. Há avanços na virtualização da aprendizagem, mas só conseguem arranhar superficialmente a estrutura pesada em que estão estruturados os vários níveis de ensino (Moran, 2013, p. 89).

Ainda, segundo o autor, agora corroborando com as proposições de Lévy (2004), aponta que as mudanças ocasionadas pela internet para as trocas de ideias e cooperações, geraram uma prática de inteligência coletiva, pois cada um comenta, compartilha, interage na tentativa de construir um saber comum, enquanto tem liberdade de propor, seguindo o princípio de falseabilidade proposto por Karl Popper (1902 - 1994), teorias diferentes (Ignácio, 2015). 
Para explorar as várias possibilidades de se comunicar com a comunidade surda, é desafiadora a otimização da capacidade de invenção das pessoas, suas competências, suas experiências e memórias. Esse desenvolvimento é considerado, por Lévy (2004), como o melhor caminho para se chegar a uma cultura da inteligência coletiva, ou seja, com a constituição de uma vasta rede de pesquisas, a perspectiva é avançar em direção a uma transformação cultural de modo a favorecer a criação de conexões entre as pessoas mediadas pelas tecnologias.

Ainda, segundo Lévy (1999, p. 22), considera-se que "realmente exista três entidades: técnica, cultura e sociedade". Embora se tente separar as dimensões sociais em que o homem se situa, é praticamente impossível não considerar que uma está diretamente atrelada à outra. A tecnologia, como parte do seguimento da técnica, não deve ser analisada pelo seu impacto como se fosse uma atuante das mudanças sociais, uma vez que tomou tamanhas proporções em virtude da própria sociedade e de seus diversos grupos organizados. Nesse sentido, é preciso explorar as potencialidades desse espaço de comunicação nos espaços de formação, dando abertura ao novo e abrangendo os aspectos políticos, econômicos, culturais e sociais.

As tecnologias são produtos de uma sociedade e de uma cultura. Mas a distinção traçada entre cultura (a dinâmica das representações), sociedade (as pessoas, seus laços, suas trocas, suas relações de força) e técnica (artefatos eficazes) só pode ser conceitual (Lévy, 1999, p. 22).

A relação de informações e pessoas, potencializada pelas TDIC, possibilita a condição de capital social e continua demonstrando que estamos no início do novo momento da situação criada pelo desenvolvimento do ciberespaço e que temos um novo campo a ser explorado sobre o que é cooperação intelectual, sobre aquilo que é construir juntos ideias e selecioná-las para o melhor bem de todos, a inteligência coletiva humana (Lévy, 2004).

Com o suporte das TDIC que vem favorecendo a integração e a interação, ao mesmo tempo, em que os alunos com necessidades específicas se sentem acolhidos no processo de ensino e aprendizagem, os demais alunos aprendem a conviver com as diferenças, respeitando-as, exercendo a empatia e a paciência, virtudes bastante raras no período atual.

Segundo Moran (2006, p. 133), no contexto escolar, por muito tempo, não se valorizou o uso adequado das TDIC, desprezando tornar o processo de ensino-aprendizagem mais eficiente. Nós, indagando a respeito, encontramos algumas convicções quanto à função da escola, compreendendo que, em todos os níveis, a função é educar, transmitir conhecimentos sistematizados nas diversas áreas do ensino, desde a educação infantil até os cursos de formação profissional e de graduação, exigindo memorização das informações e reprodução para avaliações. Somado a isso, espera-se que a escola transmita valores e forme cidadãos críticos no atual momento da sociedade.

Com o crescimento exponencial do uso das TDIC, não necessariamente novas tecnologias, que vem transformando diariamente a vida cotidiana, vivemos a era da disrupção e da mudança, em que os empregos ditos operacionais deixam de existir. Novos negócios, novas profissões, mudanças sociais e culturais exigem um novo olhar para a educação, baseada no desenvolvimento de competências e habilidades, e não de conteúdo, para responder às expectativas e às exigências do século XXI.

Vale destacarmos que, para a educação, é muito importante a inovação por meio do desenvolvimento de habilidades que fomentem novas ideias e tecnologias. No entanto, enquanto as tecnologias digitais estão mudando profundamente a maneira como trabalhamos, nos comunicamos e nos divertimos por meio das mídias digitais, o mundo da educação e da aprendizagem sofreu um repentino avanço e ainda está passando pelo processo de inovação impulsionado pela necessidade de superar a pandemia com o auxílio da tecnologia o que outros setores já vivem como realidade.

Nesse aspecto, a necessidade de desenvolvimento de competências digitais vem motivando a revisitação dos currículos dos futuros docentes. A prática docente já demonstrava a importância de atualizar essas competências no século XXI e ficaram ainda mais evidente no cenário atual e pós-pandemia. 
O desenvolvimento profissional dos agentes envolvidos na mediação pedagógica das TDIC é um tema que merece um olhar cuidadoso no sentido de compreendermos como as ações formativas dos professores e intérpretes para a integração dessas tecnologias em suas práticas docentes vêm ocorrendo.

Muito embora o cenário atual da pandemia nos apresentou um senso de urgência e os desafios para as questões relacionadas à importância da cultura digital na educação, o tema já é presente nas diretrizes da Base Nacional Comum Curricular (BNCC) $)^{3}$ (Brasil, 2018) e na Base Nacional Comum para a Formação Inicial e Continuada de Professores da Educação Básica (BNC-Formação) (Brasil, 2020). A BNCC contempla e reconhece os conteúdos, bem como a importância da tecnologia e a define na competência geral 5 - Cultura Digital -, da seguinte forma:

Compreender, utilizar e criar tecnologias digitais de informação e comunicação de forma crítica, significativa, reflexiva e ética nas diversas práticas sociais (incluindo as escolares) para se comunicar, acessar e disseminar informações, produzir conhecimentos, resolver problemas e exercer protagonismo e autoria na vida pessoal e coletiva (Brasil, 2018, p. 09).

Segundo o documento, a tecnologia exerce papel fundamental na aprendizagem em todas as áreas, devendo o aluno "dominar o universo digital, sendo capaz, portanto, de fazer um uso qualificado e ético das diversas ferramentas existentes e de compreender o pensamento computacional e os impactos da tecnologia na vida das pessoas e da sociedade" (Brasil, 2018, p. $69)$.

O desenvolvimento de competências e habilidades digitais é fundamental, no século XXI, para toda a sociedade e a educação possui uma responsabilidade central neste processo. Competências e habilidades digitais essas que não estão relacionadas apenas a conhecimentos técnicos, mas envolvem as capacidades humanas, como colaboração, empatia e resiliência.

Para Lévy (2004), a inteligência coletiva não é limitada à exposição de conteúdos e o retorno disso, através das interações em fóruns e chats, uma vez que o sentido é bem mais amplo e depende da hipertextualidade de reconhecer o outro como sujeito com inteligência através das conexões que fazemos potencializando os conhecimentos. Com isso, os saberes depositados nos indivíduos se entrelaçam como numa teia e se complementam, independentemente de sua língua, classe social, faixa etária, civil, pois cada conhecimento complementa a sua formação.

Reconhecemos que houve conquistas na área clínica e um considerável salto qualitativo por conta dos últimos acontecimentos, como a pandemia Covid-19. No campo educacional, em certa medida, com estratégias e boa vontade, as coisas vêm acontecendo na perspectiva da inclusão. O acesso ao conhecimento por meio de Libras com suporte tecnológico se evidencia cada vez mais. Além disso, com os surdos ocupando espaços no meio acadêmico, surge a necessidade de criação de sinais nas mais diversas áreas do saber, bem como a criação de aplicativos ou meios digitais que possam complementar e disseminar os conhecimentos científicos.

\section{Considerações Finais}

Evidenciou-se neste estudo as dicotomias entre educação e saúde, as concepções da surdez, bem como as perspectivas que as TDIC são utilizadas, ambas com o foco na qualidade de vida do sujeito surdo. A primeira como ferramentas didáticopedagógicas sendo suporte visual para o aluno surdo e a outra como tecnologia para fins de reparo no defeito orgânico do indivíduo, a surdez. A segunda, de forma geral, como as TDIC podem ser excelentes ferramentas didático-pedagógicas para

\footnotetext{
${ }^{3}$ Adotamos as concepções de competência e habilidade da BNCC: competência é definida como a mobilização de conhecimentos (conceitos e procedimentos), habilidades (práticas, cognitivas e socioemocionais), atitudes e valores para resolver demandas complexas da vida cotidiana, do pleno exercício da cidadania e do mundo do trabalho (BRASIL, 2018, p. 09). Expressas em dez competências gerais: conhecimento; pensamento científico, crítico e criativo; repertório cultural; comunicação; cultura digital; trabalho e projeto de vida; argumentação; autoconhecimento e autocuidado; empatia e cooperação; responsabilidade e cidadania.
} 
fazer com que o aluno surdo incluso possa ter acesso ao conhecimento nos mais variados contextos sociais cotidianos.

Historicamente, a língua brasileira de sinais era bastante restrita, porém, nos últimos anos, percebemos uma maior aceitação e reconhecimento social da língua. Cada vez mais pessoas estão interessadas em aprender e a disseminação da língua tem ampliado seu escopo de utilização com o avanço das mídias digitais. Dessa forma, com o uso da internet e das TDIC, de maneira geral, alavancou-se essa disseminação, considerando que levamos muito tempo para serem constituídas e usadas com propriedade, há muito ainda a ser explorado.

Nesse sentido, entender que o uso das tecnologias digitais é cultural implica demonstrá-las como fator que desencadeia novos comportamentos em relação à Libras e a comunidade usuária. Novas demandas surgem, como a criação de glossários, as traduções nas mídias e meios digitais favorecem muito todos aqueles que pensam a educação de surdos como processo cultural e sabem a importância disso tudo. Assim, reconhece-se a prática da ideia da inteligência coletiva proposta por Lévy (2004), ou seja, as trocas, os compartilhamentos melhoram a comunicação entre as pessoas, bem como compreendem melhor o outro, pois como o autor sustenta, cada um tem um savoir-faire, um jeito de saber fazer, um conhecimento próprio que compartilhado é beneficial às diferentes áreas da vida humana.

\section{Referências}

Au, A., et. al., (2019). Wireless binaural hearing aid technology for telephone use and listening in wind noise. In: Int J Audiol. 58(4): 193-199.

Barros, R. \& Olímpio, I. (2016). A inserção das novas tecnologias na formação de professores. Revista de Estudos e Pesquisas sobre Ensino Tecnológico EDUCITEC. 2(3).

Brasil. (2002). Lei 10.436, de 24 de abril de 2002. http://www.planalto.gov.br/ccivil_03/leis/2002/110436.htm

Brasil, (2018). Ministério da Educação. Base Nacional Curricular Comum - Educação é a base. Brasília, MEC-SE-SEB, CNE, CONSED, UNDIME. http://basenacionalcomum.mec.gov.br/abase/

Brasil, (2020). Conselho Nacional de Educação. (2020). Resolução No 1, de 27 de outubro de 2020. Brasília, CNE. https:/www.in.gov.br/en/web/dou//resolucao-cne/cp-n-1-de-27-de-outubro-de-2020-285609724

Bisol, C. A., Simioni, J., \& Sperb, T. (2008). Contribuições da psicologia Brasileira para o estudo da surdez. In: Psicologia: Reflexão e Crítica, 21(3), 392400 .

Bisol, C. A., Valentini, C. B., Simioni, J. L., \& Zanchin, J. (2010). Estudantes surdos no ensino superior: reflexões sobre a inclusão. In: Cadernos de Pesquisa, 40(139), 147-172.

Bisol, C. A., Bremm, E. S., \& Valentini, C. B. (2010). Blogs de adolescentes surdos: escrita e construção de sentido. In: Revista Semestral da Associação Brasileira de Psicologia Escolar e Educacional, 14(2), 291-299.

Borges, L.C., \& Salomão, N. M. R. (2003). Aquisição da linguagem, considerações da perspectiva da interação social. Psicologia: Reflexão e Crítica, 16 (2), 327-336.

Bochernitsan, D. C., (2021). Mídias Visuais: elaboração de materiais. Curso de formação continuada para professores de surdos. UFRGS.

Souza, M. T., Silva, M. D., \& Carvalho, R. (2010). Revisão integrativa: o que é e como fazer. Einstein, 8(1), $102-106$.

Carvalho, M. E., Cavalcanti, W. M. A., \& Silva, J. A. (2019). Ensino de Língua Portuguesa para surdos: uma revisão integrativa da literatura. In: Revista CEFAC. 21, 1-12.

Carvalho, D. S., \& Pedruzzi, C. M. (2019). Uso do sistema de frequência modulada por escolares com perda auditiva. In: Distúrb Comun, 31(1): 12-21.

Corrêa, Y., \& Cruz, C. R. (2019). Língua Brasileira de Sinais e Tecnologias Digitais. Penso, 188 p.

FEBRAPILS. (2020). Nota Técnica No 004. Federação Brasileira das Associações dos Profissionais Tradutores e Intérpretes e Guia-Intérpretes de Língua de Sinais. https://drive.google.com/file/d/1Zap62uLDTJ7TPKnDedaO9Z0k0IOrmvWf/view.

Fernandes, E., \& Rios, K. R. (1998). Educação com bilingüismo para crianças surdas. In: INTERCÂMBIO, VII, 13-21.

Ferrarini, R., Saheb, D., Torres, P. L. (2019). Metodologias ativas e tecnologias digitais: aproximações e distinções. In: Revista Educação em Questão. 57(52). $1-30$.

Furtado, M. A. C. M. (2013). A Interpretação In Situ e a Interpretação Remota: realização e análise cientifica de um conjunto de estudos experimentais. 494 f. Tese (Doutorado) - Curso de Tradución \& Paratradución, Universidade de Vigo, Vigo. 
Hyde, M., Punch, R., \& Komesaroff, L. (2010). Coming to a decision about cochlear implantation: parents making choices for their deaf children. In: J Deaf Stud Deaf Educ. 15(2): 162-78,

Ignácio, L. E. (2015). O progresso da Ciência: Uma análise comparativa entre Karl R. Popper e Thomas S. Kuhn. Dissertação (mestrado), Universidade Federal de Santa Catarina - Florianópolis - SC,

Julstrom, S., Kozma-Spytek, L., \& Isabelle, S. (2011). Telecoil-mode hearing aid compatibility performance requirements for wireless and cordless handsets: magnetic signal levels. In: J Am Acad Audiol. 22(8): 515-27.

Karnopp, L. B., Klein, M., \& Lazzarin, M. L. L. (2011). Cultura surda na contemporaneidade: negociações, intercorrências e provocações. Canoas: ULBRA.

Leite, S. S. (2017). Construção do roteiro do vídeo educativo para pessoas surdas sobre o uso do coito interrompido. $108 \mathrm{p}$.

Lévy, P. (1999). Cibercultura. Editora 34.

Lévy, P. (2004). A inteligência coletiva: por uma antropologia do ciberespaço. (4a ed.), Loyola.

Libório, R. M. C. et. al., (2015). Resiliência e Processos Protetivos de Adolescentes com Deficiência Física e Surdez Incluídos em Escolas Regulares. In: Rev. Bras. Ed. Esp., 21(2), 185-198.

Marques, R. F. (2020). Interpretação Remota Durante a Pandemia do Coronavirus: Um relato de experiência de interpretação no ensino superior. Curso de graduação em letras libras - bacharelado. Universidade federal de Santa Catarina. UFSC.

Moran, J. M., Masetto, M. T., \& Behrens, M. A. (2006). Novas tecnologias e mediação pedagógica. Papirus.

Moran, J. M. (2013). A Educação que desejamos: novos desafios e como chegar láPapirus.

Moreira, M. L., \& Simões, A. S. M. (2017). O uso do WhatsApp como ferramenta pedagógica no ensino de Química. In: ACTIO: Docência em Ciências. 2(3). 21-43.

OPAS, (2019). Organização Pan-Americana da Saúde. Histórico da pandemia de COVID-19. https://www.paho.org/pt/covid19/historico-da-pandemia-covid19.

Palavissini, C. F. C., \& Lima, D. F. (2021). Causas e efeitos da aquisição tardia da língua de sinais em crianças surdas: pesquisa em construção. In: 1 Encontro de pesquisas do grupo de pesquisa em Educação de surdos, subjetividades e diferenças (GPESDI). Tema: Educação e diferenças em dialogo na pandemia do covid-19. São Carlos. UFSCAR. Anais,

Palavissini, C. F. C. \& Lima, D. F. (2021). Ingresso e permanência do aluno surdo no meio universitário: enfrentamentos e superações. In: Anais do Congresso Brasileiro Interdisciplinar em Ciência e Tecnologia. Anais. Diamantina (MG) UFVJM. https//www.even3.com.br/anais/cobicet/393953INGRESSO-E-PERMANENCIA-DO-ALUNO-SURDO-NO-MEIO-UNIVERSITARIO--ENFRENTAMENTOS-E-SUPERACOES.

Palavissini, C. F. C. \& Lima, D. F. (2021). Língua de sinais e o implante coclear: uma lacuna de identidade. In: Anais do XV Congresso Nacional de Educação - EDUCERE. Inspirações, Espaços e Tempos da Educação. Anais. Curitiba - PR. Pontifícia Universidade Católica do Paraná. 3597-3607.

Perlin, G., \& Strobel, K. (2008). Fundamentos da educação de surdos. Florianópolis: UFSC.

Previtali, F. S., \& Fagiani, C. C. (2020). Trabalho e educação sob o coronavírus no Brasil. In: Lucena, Carlos. Vitali, Fabiane. Bretas, Anderson (orgs). Pandemia Covid-19: a distopia do século XXI. Uberlândia, MG: Navegando Publicações. 123-137.

Rosa, C. T. W., Trentin, M. A. S., \& Biazus, M. O. (2017). Tecnologias educacionais no ensino de física: Retrato das pesquisas nacionais. In: Revista Ensino de Ciências e Tecnologia em Revista. 2. 24-42. Jul./Dez.

Shew, A. (2020). Let COVID-19 expand awareness of disability tech. In: Nature, 581.

Smith, L. S. (2015). Tune into safety for hearing-impaired patients. In: Nursing. 45(6), 4-66.

Stinson, M. S., Elliot, L. B., \& Easton, D. (2014). Deaf/hard-of-hearing and other postsecondary learners' retention of STEM content with tablet computerbased notes. In: J Deaf Stud Deaf Educ. 19(2): 251-69.

Vercelli, L. C. A. (2020). Aulas remotas em tempos de Covid-19: a percepção de discentes de um programa de mestrado profissional em educação. In: Revista @mbienteeducação. Universidade Cidade de São Paulo, 13(2), 47-60. 